\title{
New Activity Measurement Technique by Vacuum-Sealed Quartz Cell/Atomic Absorption Spectrophotometer Combination and Its Application to Liquid Bi-In Binary System
}

\author{
Shigeatsu Nakazawa ${ }^{1}$, Minoru Sunada ${ }^{2}$, Takeshi Azakami ${ }^{3}$ and Tetsuya Nagasaka ${ }^{1}$ \\ ${ }^{1}$ Graduate School of Environmental Studies, Tohoku University, Sendai 980-8579, Japan \\ ${ }^{2}$ Sunada Kogyo, Co., Ltd., Tonami 909-1357, Japan \\ ${ }^{3}$ Emeritus Professor, Tohoku University, Japan
}

The problems concerned with non-proportionality between the absorbance and the vapor density and its dependence on the vapor temperature, which are inherently encountered by vacuum-sealed quartz cell/atomic absorption spectrophotometry combination, were solved through model calculations in this study. Model calculations revealed that "colligated analytical-curve" is useful. Activities of Bi and In in the $\mathrm{Bi}$-In liquid alloy were measured over the entire composition range at the temperature from 850 to $1050 \mathrm{~K}$. An alloy was vacuum-sealed in a quartz cell and heated at the temperature of interest. The absorption for Bi $307 \mathrm{~nm}$ radiation from $\mathrm{Bi}$ lamp was measured for $\mathrm{Bi}$ atom vapor in the cell. By heating a pure metal as a standard and measuring the absorbance as a function of the temperature, a colligated analytical-curve for Bi atom vapor was constructed and used for conversion of the absorbance to the vapor density. Bi activity was determined as the ratio of the Bi atom vapor density over the alloy to that over a pure metal. The same procedure was applied to the In $304 \mathrm{~nm}$ radiation from In lamp and In activity was determined independently of Bi. Thermodynamic behavior of the Bi-In liquid alloy was optimized with a sub-regular solution model by taking into account activity data obtained in this study. The agreement between activities optimized in this study and those in the literature was fairly good. The model also well predicted the liquidus curve on the Bi side and the heat of mixing in Bi-In binary, both of which are comparable with the literature values. Finally it was concluded that by constructing colligated analytical-curves the vacuum-sealed quartz cell/atomic absorption spectrophotometer combination was established as a useful technique to measure the activities of elements in alloy systems.

(Received March 30, 2004; Accepted July 28, 2004)

Keywords: atomic-absorption-spectrophotometry, vacuum-sealed quartz cell, colligated analytical curve, model calculation, thermodynamic activity, bismuth, indium, liquid alloy, liquidus curve, heat of mixing

\section{Introduction}

Atomic absorption spectrophotometry (AAS) has several advantages; it is relatively free of interference by other elements, has a high sensitivity and offers direct information about monatomic species.

In order to determine the thermodynamic activity of the alloy components in this study, the nebulizer-burner was removed from a commercial instrument of atomic absorption spectrophotometer and a vacuum-sealed quartz cell with an alloy sample inside was placed instead as shown in Figs. 1 and 2. The cell with the sample was heated at a fixed temperature of interest in a horizontal tube-furnace.

The vapor in the quartz cell does not flow out but it reaches static equilibrium with the metal phase. The density of the equilibrium atom vapor can be determined by measuring the absorption for emission from a hollow-cathode lamp.

Different from common atomization systems, such as flame atomization system and electrothermal atomizer, ${ }^{1,2)}$ the vapor inside the quartz vacuum-sealed cell is at a low temperature (below $1300 \mathrm{~K}$ ) and a low density (neither carrier gas nor combustion gas is there). Then an a priori proportionality between the atomic absorbance and the atomic vapor density is not guaranteed; the activity of a constitutional element, therefore, can not always be determined as the ratio of atomic absorbance. The analytical curve should be constructed by using some standard substances before the absorbance measured for the vapor over the sample alloy is converted to the atomic vapor density.

Pure $\mathrm{Bi}$ and In metals were used as standard substances in this study. The atomic vapor density over a pure metal was

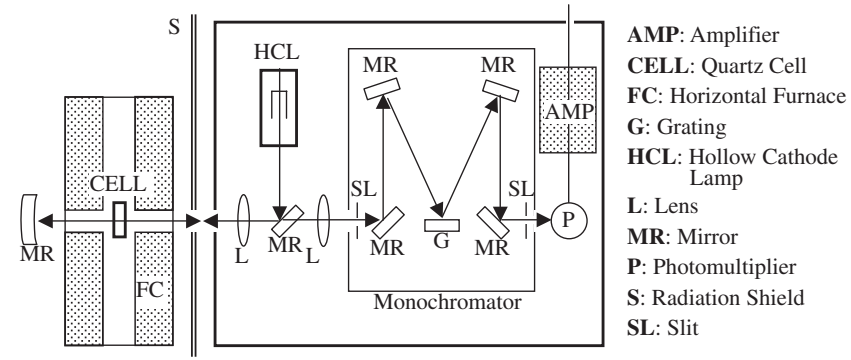

Fig. 1 Plan view of experimental arrangement for the activity-determination by using vacuum-sealed quartz cell/atomic absorption spectrophotometer.

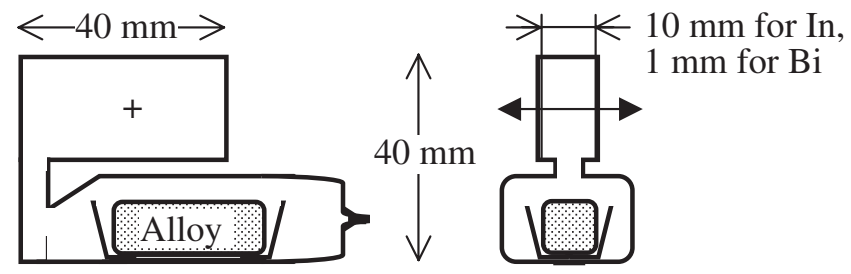

Fig. 2 Quartz cell. Light beam was introduced at + point in a direction perpendicular to the window.

calculated as a function of the temperature by referring to literature data.

\section{Model Calculation}

Model calculations were executed in order to obtain the theoretical relationships between the absorbance and the 
vapor density for the following situation:

1) Commercial hollow-cathode lamps for the elements of interest are used as spectral light sources.

2) The sample to study is vacuum-sealed in a transparent quartz cell and heated at a temperature between $600 \mathrm{~K}$ and $1200 \mathrm{~K}$.

3) Radiation emitted from the lamp passes the vapor in equilibrium with the sample alloy in the cell.

4) Intensities of the spectral line incident on and transmitted through the vapor are measured by using the monochromator/detector system that is installed to the commercial spectrophotometer.

\subsection{Assumptions}

A model was constructed based on the following assumptions.

\subsubsection{Emission in the hollow cathode}

It is assumed that the hollow-cathode line has a spectral width corresponding to Doppler temperature of $T_{\mathrm{C}}$. It is also assumed that the monochromator is always adjusted to the spectral center of the line and it has a resolving power represented by a Gaussian function. The product of two Gaussian functions, one of which represents the profile of an emitted line inside the hollow-cathode and the other of which represents the resolving power of the monochromator, forms another Gaussian function. In this study which deals with the product of two functions, the Doppler temperature $T_{\mathrm{C}}$ is redefined, for simplicity, as the quantity referring to the width of this combined function. Thus, the spectral profile of the line of interest is expressed as

$$
\exp \left(-\xi^{2}\right)
$$

The quantity $\xi$ is a dimensionless variable defined as

$$
\xi \equiv \frac{v-\bar{v}}{\bar{v}} \frac{c}{\sqrt{\frac{2 R T_{\mathrm{C}}}{M}}}
$$

where

$v$ : the frequency $[=] \mathrm{s}^{-1}$,

$M$ : the molar mass of the atom $[=] \mathrm{kg} \mathrm{mol}^{-1}$,

$\bar{v}$ : the central frequency $[=] \mathrm{s}^{-1}$,

$T_{\mathrm{C}}$ : the Doppler temperature of the line $[=] \mathrm{K}$,

$c$ : the light velocity $[=] \mathrm{m} \mathrm{s}^{-1}$,

$R$ : the gas constant $[=] \mathrm{J} \mathrm{mol}^{-1} \mathrm{~K}^{-1}$.

\subsubsection{Self-absorption inside the lamp}

A cloud of atoms at the mouth of or outside the hollowcathode causes self-absorption. It is assumed that the cloud has a uniform temperature and that the absorption coefficient profile shown by the cloud has a Doppler-broadening corresponding to the temperature $T_{\mathrm{S}}$.

The attenuating factor that acts on the intensity of the line passing the cloud is then expressed as

$$
S \equiv \exp \left[-Q_{\mathrm{S}} \exp \left(-\frac{T_{\mathrm{C}}}{T_{\mathrm{S}}} \xi^{2}\right)\right],
$$

where

$Q_{\mathrm{S}}$ : a quantity combining the effects of the density and the path-length of the cloud (dimensionless)

$T_{\mathrm{S}}$ : the Doppler temperature of the absorption coefficient profile $[=] \mathrm{K}$.

\subsubsection{Intensity of the incident beam}

The resultant intensity of radiation emitted by a hollowcathode lamp is given by

$$
I_{0}=\int_{-\infty}^{+\infty} \exp \left(-\xi^{2}\right) S d \xi
$$

The resolving power of the monochromator that is installed for AAS is not high. Then the intensity determined experimentally corresponds to the quantity integrated with respect to the frequency over a finite range.

An infinite integration is introduced just for simplicity of notation. It does not spoil the mathematical rigor. Numerical integrations within the interval $\xi=-5$ to $\xi=+5$ give accurate results.

\subsubsection{Absorption by the vapor inside the cell}

The specimen is held in a transparent cell. The vapor in the cell is in the equilibrium with the sample. When the atomic spectral line passes the cell, the intensity of the incident line is attenuated by a factor

$$
K \equiv \exp \left[-\sigma \frac{f}{\bar{\nu}} \sqrt{\frac{M}{R T}} \frac{n}{V} l \exp \left(-\frac{T_{\mathrm{C}}}{T} \xi^{2}\right)\right],
$$

where

$T$ : the temperature of the vapor and the sample in the cell $[=] \mathrm{K}$,

$f$ : the oscillator strength of the atomic spectral line (dimension-less),

$n / V$ : the density of the atom at the level where the absorption occurs $[=] \mathrm{mol} \mathrm{m}^{-3}$,

$l$ : the path-length of cell, i.e., the thickness of the vapor layer in the cell $[=] \mathrm{m}$.

A conversion factor $\sigma$ is a constant and consists of several quantities

$$
\begin{aligned}
\sigma & \equiv \frac{\pi F^{2}}{\frac{10^{11} \mathrm{Fm}^{-1}}{\left(100 c \mathrm{~m}^{-1} \mathrm{~s}\right)^{2}} M_{\mathrm{e}} c} \times \frac{c}{\sqrt{2 \pi}} \\
& =1.91154157 \times 10^{26} \mathrm{~mol}^{-1} \mathrm{~m}^{3} \mathrm{~s}^{-2},
\end{aligned}
$$

where

$F$ : the Faraday constant $[=] \mathrm{C} \mathrm{mol}^{-1}, \quad M_{\mathrm{e}}$ : the molar mass of electron $[=] \mathrm{kg} \mathrm{mol}^{-1}$.

$K$ gives the profile of the spectral absorption by the vapor in the cell. In the case of the cell with a vacuum-sealed sample the total pressure is quite low. Thus it is enough to take into account only the Doppler broadening of the absorption coefficient. The Lorentz broadening by the vapor is neglected.

\subsubsection{Intensity of transmitted light}

The resultant intensity of transmitted radiation is represented as an integrated quantity

$$
I=\int_{-\infty}^{+\infty} \exp \left(-\xi^{2}\right) S K d \xi
$$

\subsubsection{Absorbance determined experimentally}

Practical absorbance is determined as 


$$
A \equiv-\log \frac{I}{I_{0}}=-\log \frac{\int_{-\infty}^{+\infty} \exp \left(-\xi^{2}\right) S K d \xi}{\int_{-\infty}^{+\infty} \exp \left(-\xi^{2}\right) S d \xi}
$$

Any factors common to the numerator and the denominator cancel out and do not influence the observed absorbance. Therefore, it is not necessary to consider any preexponential factor in the equation for the intensity profile of the hollow-cathode emission.

\subsection{Parameters}

In the next section model calculations based on the assumptions above are carried out to determine the relationships between the absorbance $A$ and the vapor density $n / V$ in a cell.

Parameters included are $R T_{\mathrm{C}} / M[=] \mathrm{m}^{2} \mathrm{~s}^{-2}, R T_{\mathrm{S}} / M[=]$ $\mathrm{m}^{2} \mathrm{~s}^{-2}, Q_{\mathrm{S}}, R T / M[=] \mathrm{m}^{2} \mathrm{~s}^{-2}$ and $f l / \bar{v}[=] \mathrm{ms}$. Once a spectral line is selected for the element of interest, values $f$ and $\bar{v}$ can be taken from the literature. ${ }^{3,4)}$ Parameters, $T_{\mathrm{C}}, T_{\mathrm{S}}$ and $Q_{\mathrm{S}}$, do not change as long as the same lamp is operated under the same conditions. Those parameters are fixed to arbitrary values. The cell temperature $T$ is also fixed to some value of interest. The path-length $l$ of the cell is fixed to $0.01 \mathrm{~m}$.

The vapor density $n / V$ is varied from its upper limit, which corresponds to saturation. Literature ${ }^{5)}$ is consulted for equilibrium pressures of pure elements. Boltzmann distribution, which describes the atomic population of the energy states, is assumed in order to derive the upper limit of $n / V$ from the vapor pressure of the pure element. Information on atomic energy levels is available from the literature. ${ }^{4)}$

\subsection{Numerical calculation}

Numerical integrations within the interval $\xi=-5$ to $\xi=$ +5 are executed by using a trapezoidal approximation, where the interval is divided to 1000 sub-intervals.

The vapor density $n / V$ is varied stepwise from its upper limit and attenuated by a factor $10^{-0.2}$ successively.

\subsection{Results of calculation}

Ordinarily analytical curves are shown in the form of $A$ vs. $n / V$. In the following sections, however, the results are shown in a $\log -\log$ scale. Proportionality between $A$ and $n / V$ is reflected as a straight line with a slope of unity in a log-log scale.

\subsubsection{Analytical curves for $\mathrm{Ca}$ vapor and $\mathrm{Zn}$ vapor}

Figure 3 shows the results of calculation for Ca $422.7 \mathrm{~nm}$ $\left(M=0.040078 \mathrm{~kg} \mathrm{~mol}^{-1}, f=0.28, \bar{v}=709.3 \mathrm{THz}\right)$ and $\mathrm{Zn}$ $307.6 \mathrm{~nm} \quad\left(M=0.06539 \mathrm{~kg} \mathrm{~mol}^{-1}, f=0.0016, \bar{v}=974.6\right.$ $\mathrm{THz}$ ). As tentative values, $T_{\mathrm{C}}, T_{\mathrm{S}}$ and $Q_{\mathrm{S}}$ are set to $2000 \mathrm{~K}$, $1000 \mathrm{~K}$ and 1.19 for $\mathrm{Ca} 422.7 \mathrm{~nm}$ and $2400 \mathrm{~K}, 2000 \mathrm{~K}$ and 1.40 for $\mathrm{Zn} 307.6 \mathrm{~nm}$, respectively. The high-end of each curve (open circle in Fig. 3) corresponds to the saturated vapor over a pure liquid, the pressure of which is shown in literature $^{5)}$ and expressed by the following equations: for $\mathrm{Ca}$

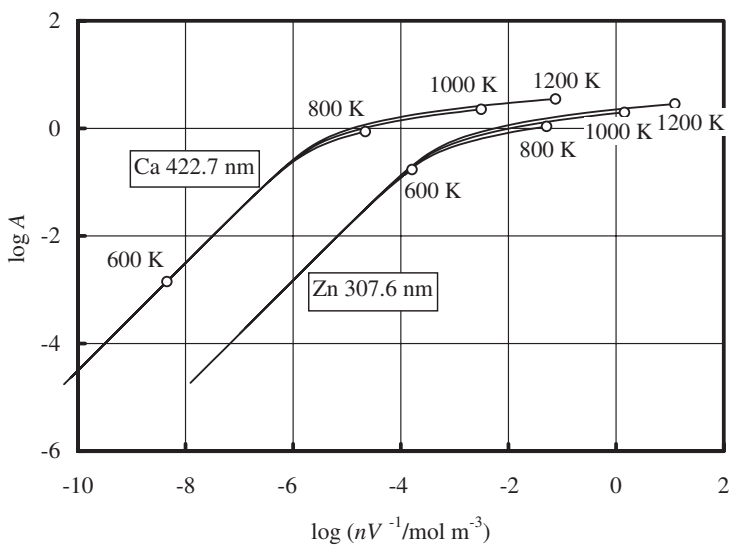

Fig. 3 Analytical curves for a $\mathrm{Ca} 422.7 \mathrm{~nm}$ line and for a $\mathrm{Zn} 307.6 \mathrm{~nm}$ line. Model calculation. $T_{\mathrm{C}}=2000 \mathrm{~K}, T_{\mathrm{S}}=1000 \mathrm{~K}$ and $Q_{\mathrm{S}}=1.19$ for $\mathrm{Ca}$ and $T_{\mathrm{C}}=2400 \mathrm{~K}, T_{\mathrm{S}}=2000 \mathrm{~K}$ and $Q_{\mathrm{S}}=1.40$ for $\mathrm{Zn}$. Open circles correspond to the saturated vapors.

$$
\begin{aligned}
\log P^{\circ} / \mathrm{Pa}= & 8.6982-9235.94(T / \mathrm{K})^{-1} \\
& +0.90127 \log (T / \mathrm{K})-0.00074986(T / \mathrm{K}) \\
& -2017(T / \mathrm{K})^{-2}
\end{aligned}
$$

and for $\mathrm{Zn}$

$$
\begin{aligned}
\log P^{\circ} / \mathrm{Pa}= & 6.6750-5.569 .09(T / \mathrm{K})^{-1} \\
& +1.16161 \log (T / \mathrm{K}) \\
& -0.00032517(T / \mathrm{K})-186878(T / \mathrm{K})^{-2}
\end{aligned}
$$

The relationship between $\log A$ and $\log n / V$ depends on the vapor temperature. Therefore analytical curve of the form $\log A$ vs. $\log n / V$, even if it is available, is not convenient to use. The high absorbance observed for the vapor at $923 \mathrm{~K}$, for example, cannot be converted to the vapor density unless the curve for the vapor at the temperature of interest is available. A curve passing a series of open circles neither has any meaning nor can be used for the purpose of interpolation.

All curves look to overlap each other when each is moved along a straight line of a slope unity. As common displacement for $\log A$ and $\log n / V$, a magnitude of $\log (T / \mathrm{K})^{-1}$ seems to give a fairly good overlapping.

\subsubsection{Colligated analytical-curves for $\mathrm{Ca}$ vapor and $\mathrm{Zn}$ vapor}

Figure 4 shows the convergence of the redrawn curves. The magnitude of common displacement to give convergence, $\log (T / \mathrm{K})^{-1}$, is determined just by trial and error.

Although all curves coincide essentially with each other, any physically plausible explanation for the displacement $\log (T / \mathrm{K})^{-1}$ has not yet been found.

An analytical curve of the form $\log \left[A(T / \mathrm{K})^{-1}\right]$ vs. $\log \left[\left(n V^{-1} / \mathrm{mol} \mathrm{m}^{-3}\right)(T / \mathrm{K})^{-1}\right]$ is hereafter referred to as "colligated analytical-curve." All of the open circles lie on the colligated analytical-curve. Convergence of analytical curves to a colligated analytical-curve is fine.

Once a set of parameters $\left(R T_{\mathrm{C}} / M, R T_{\mathrm{S}} / M, Q_{\mathrm{S}}\right.$ and $\left.f l / \bar{v}\right)$ are fixed, the colligated analytical-curve is obtained as a curve which itself is independent of the vapor temperature $T$.

A colligated analytical-curve corresponds uniquely to a set of parameters. 


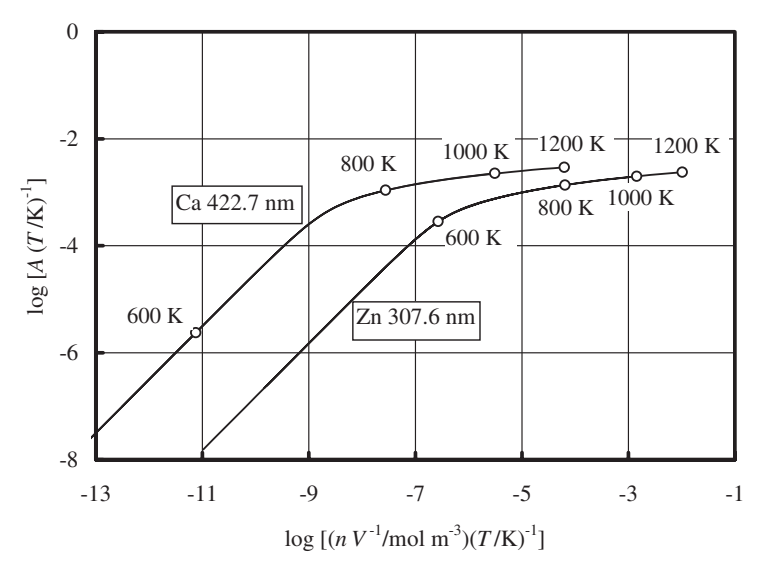

Fig. 4 Colligated analytical-curves for a $\mathrm{Ca} 422.7 \mathrm{~nm}$ line and for a $\mathrm{Zn}$ $307.6 \mathrm{~nm}$ line. Model calculation. $T_{\mathrm{C}}=2000 \mathrm{~K}, T_{\mathrm{S}}=1000 \mathrm{~K}$ and $Q_{\mathrm{S}}=1.19$ for $\mathrm{Ca}$ and $T_{\mathrm{C}}=2400 \mathrm{~K}, T_{\mathrm{S}}=2000 \mathrm{~K}$ and $Q_{\mathrm{S}}=1.40$ for $\mathrm{Zn} . T$ is the temperature of the vapor.

Experimentally it is easy to construct a colligated analytical-curve. When absorbance values $A$ are measured for vapors over a pure metal at various temperatures $T$ and the results are plotted in a $\log \left[A T^{-1}\right]$ vs. $\log \left[n V^{-1} T^{-1}\right]$ diagram, a series of plots will form a colligated analyticalcurve.

\subsubsection{A numerical approximation of a colligated ana- lytical-curve: a unified equation}

An analytical curve and therefore a colligated analyticalcurve contain integrals of exponential functions and cannot be reduced to any simple but strict expressions. As a numerical approximation, however, those are reproduced by simple and unified equations with two dimensionless parameters $a$ and $b$ :

$$
\begin{aligned}
\log \frac{n V^{-1}}{\mathrm{~mol} \mathrm{~m}^{-3}}\left(\frac{T}{\mathrm{~K}}\right)^{-1}= & a+\log A\left(\frac{T}{\mathrm{~K}}\right)^{-1} \\
& +\exp \left\{3.4 \times\left[\log A\left(\frac{T}{\mathrm{~K}}\right)^{-1}+b\right]\right\}
\end{aligned}
$$

The unified equation is not a theoretical one. The degree of approximation is satisfactory. The colligated analyticalcurves above are precisely reproduced by unified equations with $(a, b)=(-5.4984,+2.9292)$ for $\mathrm{Ca} 422.7 \mathrm{~nm}$ and $(a, b)=(-3.1753,+3.0378)$ for $\mathrm{Zn} 307.6 \mathrm{~nm}$.

A unified equation is easily fitted to an experimental relationship between $\log \left[A T^{-1}\right]$ and $\log \left[n V^{-1} T^{-1}\right]$. Once parameters $a$ and $b$ are determined, the unified equation as a "working curve" can be conveniently used for converting the absorbance $A$ to the vapor density $n V^{-1}$.

\section{Experimental}

\subsection{Conditions}

HITACHI Type 207 atomic absorption spectrophotometer was used. The monochromator was of Czerny-Turner arrangement and with gratings of $40 \times 40 \mathrm{~mm}$ size. Hollow-cathode lamps were operated at $10 \mathrm{~mA}$. The background correction was done by measuring absorption of nonresonance lines close to the wavelengths of the absorption lines: $306.1 \mathrm{~nm}$ line close to $\mathrm{Bi}$ line $(306.8 \mathrm{~nm}$, resonance) and $305.1 \mathrm{~nm}$ line close to In line $(303.9 \mathrm{~nm}$, resonance).

Metals of $99.999+\%$ purity were used for preparation of samples. A sample was loaded in a high-purity alumina boat and vacuum-sealed in a quartz cell. Windows of a cell were made of optical-flat quartz plates $(W 40 \mathrm{~mm} \times H 20 \mathrm{~mm})$. $1 \mathrm{~mm}$ path-length cells were used for $\mathrm{Bi} 307 \mathrm{~nm}$ radiation and $10 \mathrm{~mm}$ cells were used for In $304 \mathrm{~nm}$ radiation.

Electric furnace had a bore, $0.017 \mathrm{~m}$ in diameter, for transmission of the light beam. The temperature gradient of less than $1 \mathrm{~K}$ over $0.12 \mathrm{~m}$ was maintained at the hot zone of the furnace. The temperature of the sample was measured with a calibrated R-thermocouple in contact with the cell.

The temperature of the cell was raised or lowered to a desired level at a rate of about $\pm 0.04 \mathrm{~K} \cdot \mathrm{s}^{-1}$. By measuring the absorbance after the cell was held at the desired temperature for about $6000 \mathrm{~s}$, reproducible results could be obtained regardless of prior temperature; it was evident that equilibrium values were measured.

\subsection{Unified equations for $\mathrm{Bi}$ vapor and for In vapor}

The literature values ${ }^{5)}$ for the vapor pressure of pure $\mathrm{Bi}$ liquid and pure In liquid were fitted to the following equations and used to estimate the vapor pressures in the construction of analytical curves:

for $\mathrm{Bi}$ atomic vapor over a pure $\mathrm{Bi}$ liquid

$$
\begin{aligned}
\log P^{\circ} / \mathrm{Pa}= & 0.6575-8553.17(T / \mathrm{K})^{-1} \\
& +2.95523 \log (T / \mathrm{K})-0.0004420(T / \mathrm{K}) \\
& -344112(T / \mathrm{K})^{-2}
\end{aligned}
$$

and for In atomic vapor over a pure In liquid

$$
\begin{aligned}
\log P^{\circ} / \mathrm{Pa}= & 8.5195-12006.44(T / \mathrm{K})^{-1} \\
& +0.54849 \log (T / \mathrm{K})-0.00009809(T / \mathrm{K}) \\
& -82545(T / \mathrm{K})^{-2}
\end{aligned}
$$

The absorbance values of a $306.8 \mathrm{~nm}$ line by the Bi vapor at $834 \mathrm{~K}-890 \mathrm{~K}$ in $1 \mathrm{~mm}$ path-length cell are shown in Fig. 5 and expressed by a unified equation

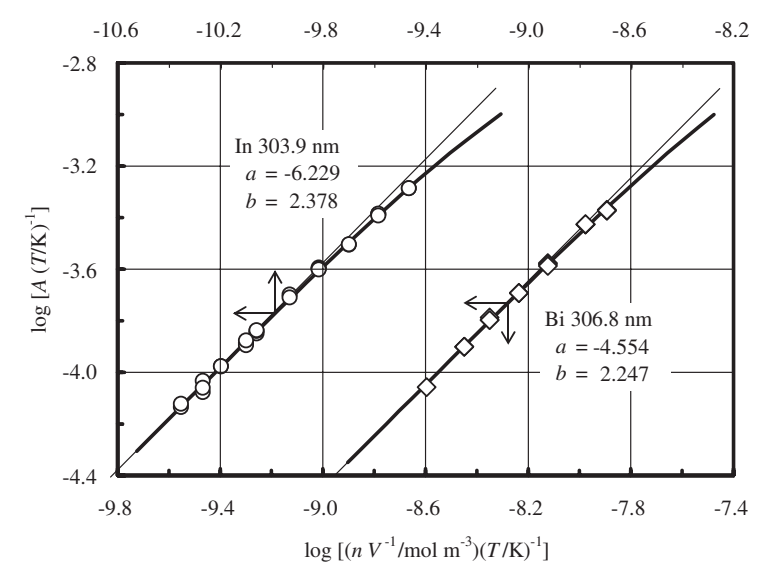

Fig. 5 Working curves for Bi vapor $(306.8 \mathrm{~nm}, 10 \mathrm{~mA}, 1 \mathrm{~mm}$ path-length cell) and for In vapor $(303.9 \mathrm{~nm}, 10 \mathrm{~mA}, 10 \mathrm{~mm}$ path-length cell). Curves correspond to unified equations. 


$$
\begin{aligned}
\log & \frac{n V^{-1}}{\mathrm{~mol} \mathrm{~m}^{-3}}\left(\frac{T}{\mathrm{~K}}\right)^{-1} \\
= & -4.554+\log A\left(\frac{T}{\mathrm{~K}}\right)^{-1} \\
& \quad+\exp \left\{3.4 \times\left[\log A\left(\frac{T}{\mathrm{~K}}\right)^{-1}+2.247\right]\right\}
\end{aligned}
$$

Absorbance values of a $303.9 \mathrm{~nm}$ line by the In vapor at 892-959 K in $10 \mathrm{~mm}$ path-length cell are also shown in Fig. 5 and expressed by a unified equation

$$
\begin{aligned}
\log & \frac{n V^{-1}}{\mathrm{~mol} \mathrm{~m}^{-3}}\left(\frac{T}{\mathrm{~K}}\right)^{-1} \\
= & -6.229+\log A\left(\frac{T}{\mathrm{~K}}\right)^{-1} \\
& +\exp \left\{3.4 \times\left[\log A\left(\frac{T}{\mathrm{~K}}\right)^{-1}+2.378\right]\right\}
\end{aligned}
$$

\subsection{Determination of activities in the Bi-In system}

The absorbance values of $\mathrm{Bi} 306.8 \mathrm{~nm}$ line and $\mathrm{In} 303.9 \mathrm{~nm}$ line were measured for the vapors over Bi-In alloys at various temperatures. By referring to the working curves (14) and (15) an absorbance-value was converted to the vapor density, which was then divided by the vapor density of a pure liquid to derive the activity $a_{\mathrm{Bi}(1)}$ or $a_{\mathrm{In}(1)}$. The results are shown in Figs. 6 and 7.

\subsection{Optimization of thermodynamic parameters}

It was assumed that the excess Gibbs energy, $\Delta G^{\mathrm{xs}}$, of the liquid Bi-In alloy is expressed by the equation of RedlichKister type:

$$
\begin{aligned}
\Delta G^{\mathrm{xs}}= & X_{\mathrm{Bi}} X_{\mathrm{In}}\left\{\Omega^{(0)}+\Omega^{(1)}\left(X_{\mathrm{Bi}}-X_{\mathrm{In}}\right)\right. \\
& \left.+\Omega^{(2)}\left(X_{\mathrm{Bi}}-X_{\mathrm{In}}\right)^{2}+\cdots\right\} \\
= & X_{\mathrm{Bi}} X_{\mathrm{In}}\left\{\left[a^{(0)}+b^{(0)} T\right]+\left[a^{(1)}+b^{(1)} T\right]\left(X_{\mathrm{Bi}}-X_{\mathrm{In}}\right)\right. \\
& \left.+\left[a^{(2)}+b^{(2)} T\right]\left(X_{\mathrm{Bi}}-X_{\mathrm{In}}\right)^{2}+\cdots\right\} .
\end{aligned}
$$

Then the enthalpy of mixing, $\Delta H_{\text {mix }}$, is expressed as

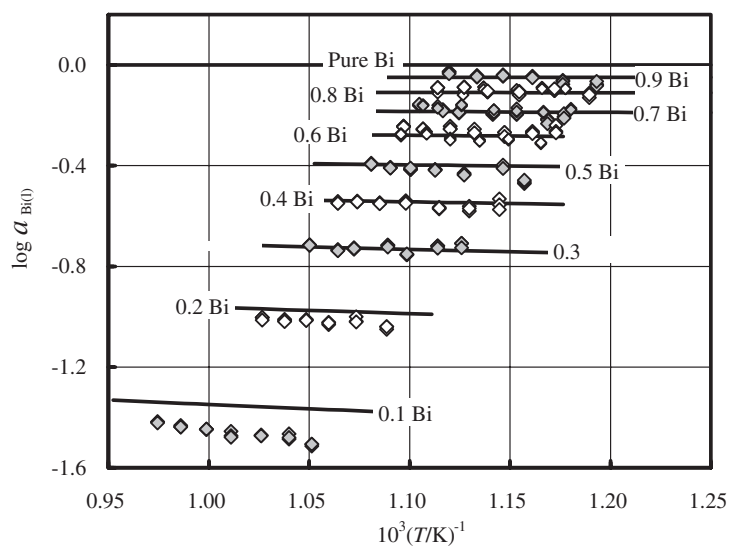

Fig. 6 Activities of $\mathrm{Bi}(\mathrm{l})$ in the $\mathrm{Bi}-\mathrm{In}$ system as a function of the temperature. The data obtained for the alloy of $X_{\mathrm{Bi}}=0.1$ were ignored in the parameter-fitting procedure.

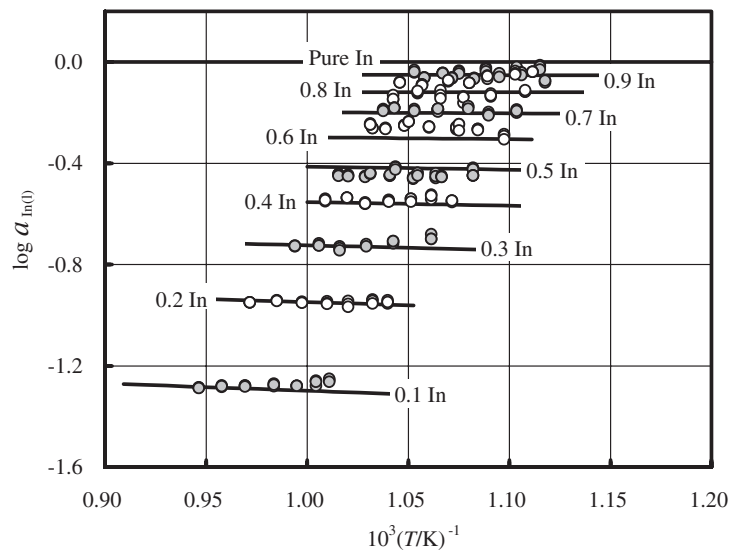

Fig. 7 Activities of $\operatorname{In}(1)$ in the Bi-In system as a function of the temperature.

$$
\begin{aligned}
\Delta H_{\mathrm{mix}}= & X_{\mathrm{Bi}} X_{\mathrm{In}}\left\{a^{(0)}+a^{(1)}\left(X_{\mathrm{Bi}}-X_{\mathrm{In}}\right)\right. \\
& \left.+a^{(2)}\left(X_{\mathrm{Bi}}-X_{\mathrm{In}}\right)^{2}+\cdots\right\},
\end{aligned}
$$

whereas activity coefficients of $\mathrm{Bi}(1)$ and $\operatorname{In}(1), \gamma_{\mathrm{Bi}(1)}$ and $\gamma_{\mathrm{In}(1)}$, are expressed as follows:

$$
\begin{aligned}
\Delta \bar{G}_{\mathrm{Bi}(1)}^{\mathrm{xs}} \equiv & R T \ln \gamma_{\mathrm{Bi}(1)} \\
= & X_{\mathrm{In}}^{2}\left\{\left[a^{(0)}+b^{(0)} T\right]+\left[a^{(1)}+b^{(1)} T\right]\left(3 X_{\mathrm{Bi}}-X_{\mathrm{In}}\right)\right. \\
& \left.+\left[a^{(2)}+b^{(2)} T\right]\left(X_{\mathrm{Bi}}-X_{\mathrm{In}}\right)\left(5 X_{\mathrm{Bi}}-X_{\mathrm{In}}\right)+\cdots\right\}
\end{aligned}
$$

and

$$
\begin{aligned}
\Delta \bar{G}_{\mathrm{In}(1)}^{\mathrm{xs}} \equiv & R T \ln \gamma_{\mathrm{In}(\mathrm{l})} \\
= & X_{\mathrm{Bi}}^{2}\left\{\left[a^{(0)}+b^{(0)} T\right]+\left[a^{(1)}+b^{(1)} T\right]\left(X_{\mathrm{Bi}}-3 X_{\mathrm{In}}\right)\right. \\
& \left.\quad+\left[a^{(2)}+b^{(2)} T\right]\left(X_{\mathrm{Bi}}-X_{\mathrm{In}}\right)\left(X_{\mathrm{Bi}}-5 X_{\mathrm{In}}\right)+\cdots\right\} .
\end{aligned}
$$

Parameters were evaluated by taking into account $\mathrm{Bi}$ activity data (237 points) in Fig. 6 and In activity data (246 points) in Fig. 7. Bi activity data obtained for the alloy of $X_{\mathrm{Bi}}=0.1,21$ points of 237 points, were finally excluded in the parameter-fitting procedure. An ordinary least-squares method was used to evaluate parameters. It was found that just two parameters $a^{(0)}$ and $a^{(1)}$ are enough to give a satisfactory and reasonable results; the molten Bi-In system is approximated by a sub-regular solution. As optimum values to minimize the sum of squared residuals

$$
\begin{aligned}
S \equiv & \sum_{i=1}^{216}\left[X_{\mathrm{In}}^{2}\left\{a^{(0)}+a^{(1)}\left(3 X_{\mathrm{Bi}}-X_{\mathrm{In}}\right)\right\}\right. \\
& \left.-\left(R T \ln a_{\mathrm{Bi}(1)}-R T \ln X_{\mathrm{Bi}}\right)_{\text {observed }}\right]_{i}^{2} \\
& +\sum_{j=1}^{246}\left[X_{\mathrm{Bi}}^{2}\left\{a^{(0)}+a^{(1)}\left(X_{\mathrm{Bi}}-3 X_{\mathrm{In}}\right)\right\}\right. \\
& \left.-\left(R T \ln a_{\mathrm{In}(1)}-R T \ln X_{\mathrm{In}}\right)_{\text {observed }}\right]_{j}^{2}
\end{aligned}
$$

two parameters with $95 \%$ confidence limit were determined as

and

$$
a^{(0)}=(-7652 \pm 133) \mathrm{J} \cdot \mathrm{mol}^{-1}
$$

$$
a^{(1)}=(+982 \pm 227) \mathrm{J} \cdot \mathrm{mol}^{-1} .
$$




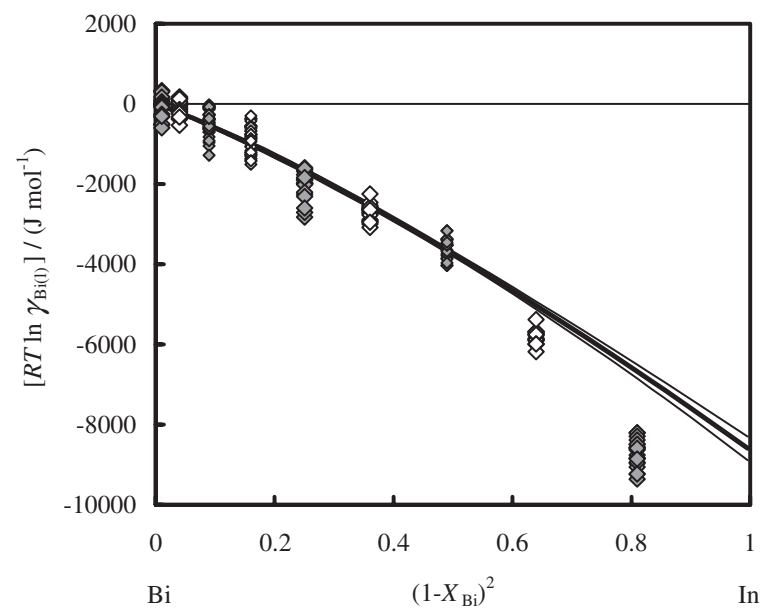

Fig. $8 R T \ln \gamma_{\mathrm{Bi}(\mathrm{l})}$ vs. $\left(1-X_{\mathrm{Bi}}\right)^{2}$. Experimental and calculated. Bi activity data for the alloy of $X_{\mathrm{Bi}}=0.1$, i.e., $\left(1-X_{\mathrm{Bi}}\right)^{2}=0.81$, were excluded before parameters were optimized. Thin lines correspond to $95 \%$ confidence limits along the calculated curve.

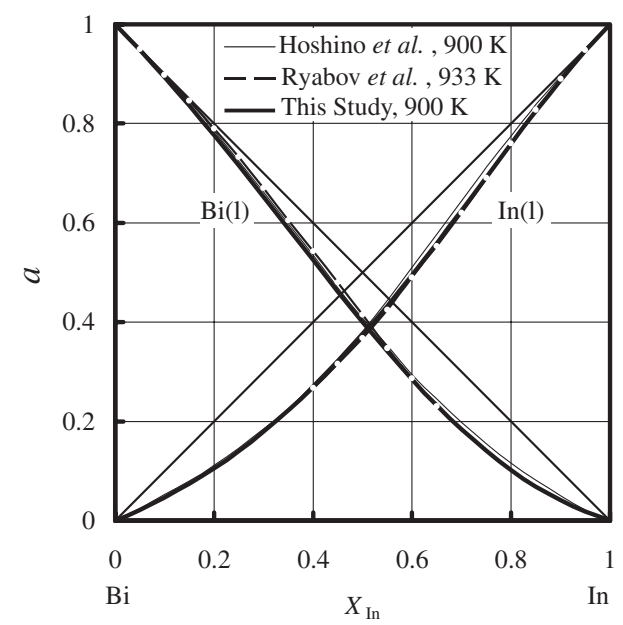

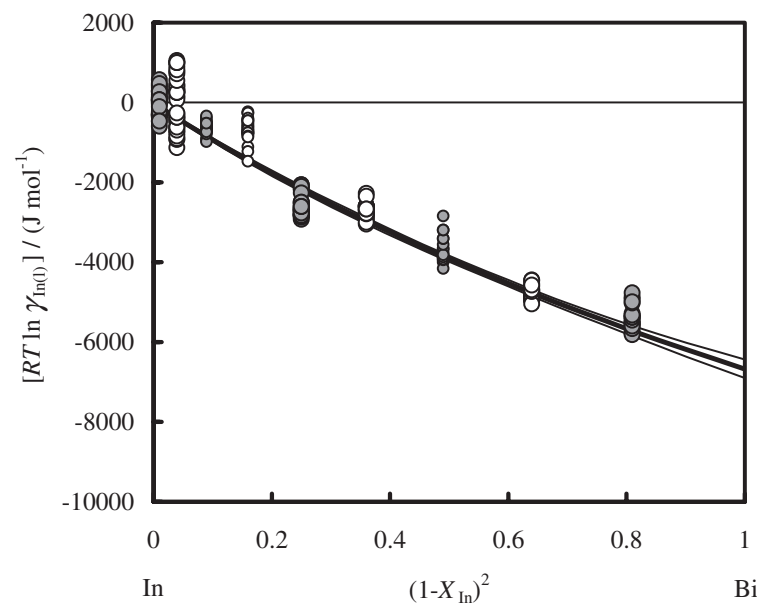

Fig. $9 R T \ln \gamma_{\text {In(l) }}$ vs. $\left(1-X_{\text {In }}\right)^{2}$. Experimental and calculated.

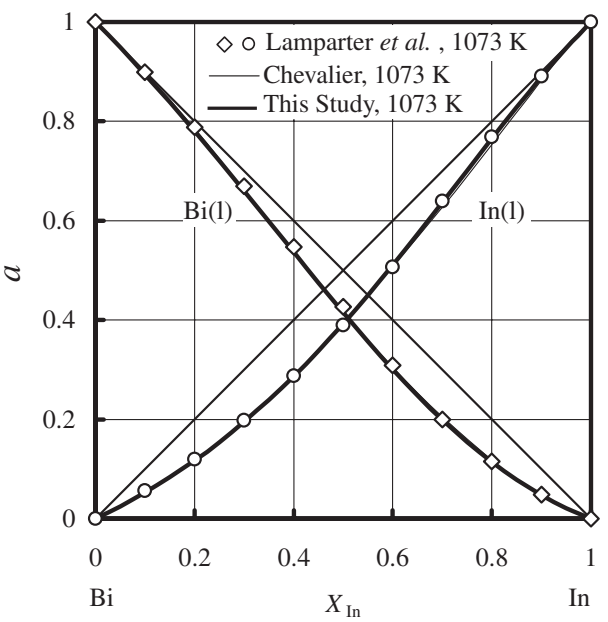

Fig. 10 (a) Activities of $\mathrm{Bi}(\mathrm{l})$ and $\mathrm{In}(1)$ calculated at $900 \mathrm{~K}$ and experimental results by Hoshino et al. ${ }^{6}$ ) and by Ryabov et al. ${ }^{7}$ (b) Activities of $\mathrm{Bi}(\mathrm{l})$ and $\mathrm{In}(\mathrm{l})$ calculated at $1073 \mathrm{~K}$, curves calculated by Chevalier ${ }^{8)}$ and experimental results obtained by Lamparter et al. $^{9 \text { ) }}$

All lines shown in Figs. 6, 7, 8 and 9 correspond to optimized results. Gibbs-Duhem relationship is inherently satisfied as far as optimized results are concerned.

\subsection{Comparison with previous data}

Activities at $900 \mathrm{~K}$ were calculated with two parameters and compared with the measurements of Hoshino et al. ${ }^{6)}$ (In EMF, $900 \mathrm{~K}$ ) and those of Ryabov and Sryvalin ${ }^{7)}$ (In EMF, $933 \mathrm{~K}$ ) in Fig. 10(a). By comprehensive optimization taking into account the different solution phases and intermetallic compounds of the Bi-In system Chevalier ${ }^{8)}$ obtained a set of eight parameters to describe the liquid Bi-In phase. In Fig. 10(b) activities calculated at $1073 \mathrm{~K}$ by using Chevalier's set of parameters and experimental results at $1073 \mathrm{~K}$ reported by Lamparter et al. ${ }^{9)}$ (Knudsen cell-mass spectrometer combination) were compared with calculations with two parameters obtained in this study. The agreement between activities calculated with two parameters and activity data available from the literature is fairly good.

By using the optimized parameters the liquidus on the $\mathrm{Bi}$ side was estimated and compared in Fig. 11 with experiments by Henry and Badwick ${ }^{10)}$ and those by Peretti and Carapella. ${ }^{11)}$ The solid solubility of $\mathrm{In}$ in $\mathrm{Bi}$ is so low $\left(X_{\text {In }} \cong 0.0001\right)$ that $\mathrm{Bi}(\mathrm{s})$ activity was regarded to be unity along the liquidus on the Bi side. The liquidus was delineated by solving the following equation:

$$
\begin{aligned}
& X_{\operatorname{In}}^{2}\left\{a^{(0)}+a^{(1)}\left(3 X_{\mathrm{Bi}}-X_{\mathrm{In}}\right)\right\} \\
& \quad+R T \ln X_{\mathrm{Bi}}+\Delta G^{\circ} \text { Bi, fusion }=0 .
\end{aligned}
$$

The standard Gibbs energy change for the fusion of Bi was compiled by Dinsdale ${ }^{12}$ as follows:

$$
\begin{aligned}
\Delta G_{\mathrm{Bi}, \text { fusion }}^{\circ}\left(\mathrm{J} \cdot \mathrm{mol}^{-1}\right)= & 11246.066-20.636510(T / \mathrm{K}) \\
& -5.955000 \times 10^{-19}(T / \mathrm{K})^{7} .
\end{aligned}
$$

The liquidus in the literature was reproduced fairly well with parameters optimized in this study. As long as the solidus temperature was fixed to $382.3 \mathrm{~K}$ according to Henry and Badwick $^{10)}$ and Peretti and Carapella, ${ }^{11)}$ the eutectic composition was estimated to be $X_{\text {In }}=0.4615$.

The enthalpy of mixing for liquid alloys was calculated by the equation 


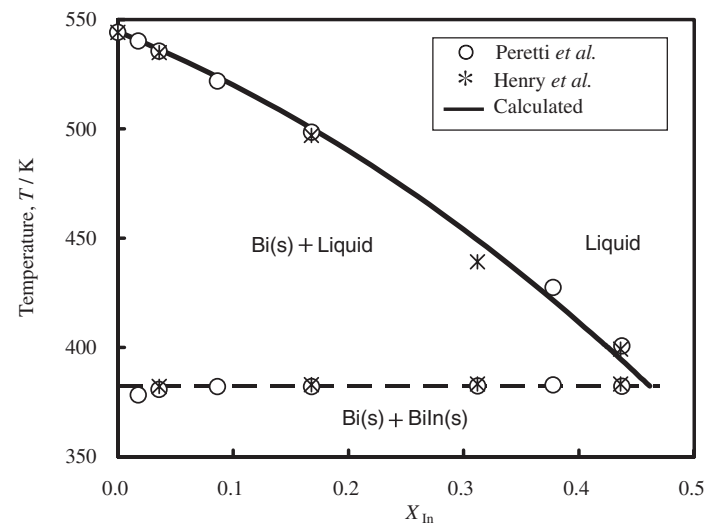

Fig. 11 The liquidus on the Bi side of the Bi-In system. The curve was calculated by using optimized parameters. $\mathrm{Bi}(\mathrm{s})$ activity was regarded to be unity along the liquidus.

$$
\Delta H_{\text {mix }}=X_{\mathrm{Bi}} X_{\mathrm{In}}\left[a^{(0)}+a^{(1)}\left(X_{\mathrm{Bi}}-X_{\mathrm{In}}\right)\right] .
$$

The results were shown in Fig. 12. The general tendency of the curve with some asymmetry coincided with experiments by Wittig and Muller ${ }^{13)}$ and those by Gregorczyk et al. ${ }^{14)}$ The heat of mixing at $X_{\mathrm{In}}=0.6$, for example, was estimated to be $\Delta H_{\text {mix }}=(-1884 \pm 37) \mathrm{J} \cdot \mathrm{mol}^{-1}$, which is comparable with $-1853 \mathrm{~J} \cdot \mathrm{mol}^{-1}$ by Wittig and Muller ${ }^{13)}$ and $-1770 \mathrm{~J} \cdot \mathrm{mol}^{-1}$ by Gregorczyk et al. ${ }^{14)}$

\subsection{The vacuum-sealed quartz cell/AAS combination for the activity measurement}

New procedure not only to retain several advantages which are inherent in AAS with a closed cell but also to overcome any problem relevant to non-proportionality between the atomic absorbance and the atomic vapor density was established in this study. Judging from the comparison of the results obtained in this study with previous data, it could be concluded that the concept of a "colligated-analytical curve" was rationalized and the vacuum-sealed quartz cell/ AAS combination is a useful technique for reliable activitymeasurements.

\section{Conclusions}

In order to apply atomic absorption spectrophotometry (AAS) to thermodynamic study on alloys, a system of vacuum-sealed quartz cell/AAS combination was constructed.

To solve the problem concerned with non-proportionality between the absorbance and the vapor density, analytical curves were drawn by using a model. Model calculations revealed that

(1) "Colligated analytical-curve" is useful.

(2) Colligated analytical-curve is independent of the temperature of the vapor in the cell.

(3) When absorbance values A are measured for vapors over a pure element at various temperatures $\mathrm{T}$ and plotted in a $\log \left[A T^{-1}\right]$ vs. $\log \left[n V^{-1} T^{-1}\right]$ diagram, a series of plots forms a colligated analytical-curve.

Colligated-analytical curves for Bi $307 \mathrm{~nm}$ radiation and for In $304 \mathrm{~nm}$ radiation were constructed by the experiments

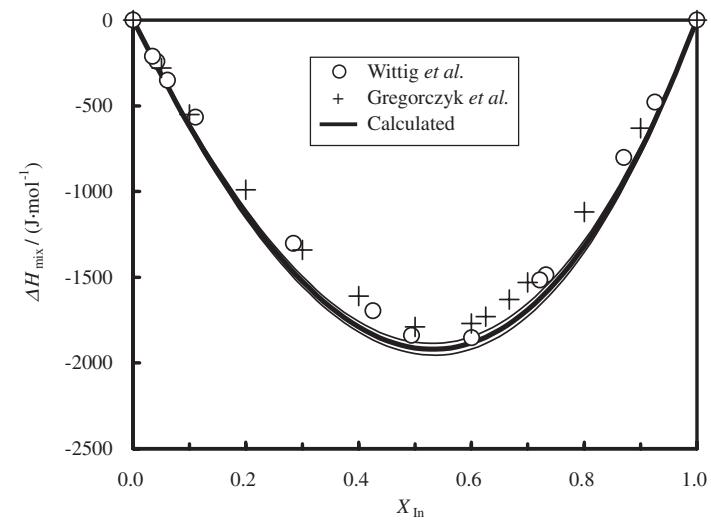

Fig. 12 Comparison between the calculated heat of mixing of the liquid Bi-In system and the literature data. ${ }^{13,14)} 95 \%$-confidence limits along the calculated curve were shown with thin lines.

using pure metals and fitted to respective working curves. By consulting with those curves the absorbance-value for the vapor over the alloy sample was converted to the vapor density and finally to the activity.

Thermodynamic behavior of the Bi-In liquid alloy was optimized with two parameters by taking into account $\mathrm{Bi}$ activity data and In activity data obtained experimentally in this study. The activities optimized agreed fairly with those in the literature. Not only the liquidus on the Bi side but also the enthalpy of mixing of the system, both of which were available from the literature, could be reproduced by using two parameters optimized in this study.

The vacuum-sealed quartz cell/AAS combination was found to be useful in measuring the activities of elements in alloy systems.

\section{REFERENCES}

1) Asha Varma: CRC Handbook of Furnace Atomic Absorption Spectroscopy, (CRC Press, Inc., Boca Raton, FLA, 1990) pp. 4-6.

2) John Edward Cantle, ed.: Atomic Absorption Spectrometry, (Elsevier Scientific Publishing, New York, NY, 1982) pp. 55-65.

3) G. F. Kirkbright and M. Sargent: Atomic Absorption and Fluorescence Spectroscopy, (Academic Press, New York, NY, 1974) pp. 541-718.

4) A. Eucken, ed.: Landolt-Bornstein Zahlenwerte und Funktionen aus Physik, Chemie, Geophysik und Technik., 6 Aufl., 1. Bd., Atom-und Molekularphysik. 1. Teil. Atome und Ionen, (Springer-Verlag, Berlin, 1950).

5) R. Hultgren, P. D. Desai, D. T. Hawkins, M. Gleiser, K. K. Kelley and D. D. Wagman: Selected Values of the Thermodynamic Properties of the Elements, (American Society for Metals, Metals Park, OH, 1973).

6) H. Hoshino, Y. Nakamura, M. Shimoji and K. Niwa: Ber. Bunsenges. 69 (1965) 414-418.

7) B. G. Ryabov and I. T. Sryvalin: Izvest. VUZ. Tsvetnaya Met. 14 (1971) 82-83.

8) P.-Y. Chevalier: CALPHAD 12 (1988) 383-392.

9) P. Lamparter, D. L. Cocke and S. Steeb: Z. Metallk. 73 (1982) 149150.

10) O. H. Henry and E. L. Badwick: Trans. AIME 171 (1947) 389-395.

11) E. A. Peretti and S. C. Carapella, Jr.: Trans. ASM 41 (1949) 947-958.

12) A. T. Dinsdale: CALPHAD 15 (1991) 317-425.

13) F. E. Wittig and E. Muller: Z. fur Phys. Chem., Neue Folge 21 (1959) 47-73.

14) Z. Gregorczyk, L. Stawarz and E. Jurzyk: J. Chem. Thermodynamics 13 (1981) 647-654. 